\title{
A TECNOLOGIA EDUCACIONAL A SERVIÇO DA TRANSFORMAÇÃO SOCIAL
}

Os crescentes avanços no campo das tecnologias causaram grandes transformações no perfil de oferta da educação, especialmente, no que se refere às mudanças na relação tempo e espaço. A educação ainda se desenvolve dentro do padrão tradicional mais conhecido, a sala de aula presencial, no entanto, com a inserção da tecnologia da informação, os processos educacionais ganham novas formas de cunho temporal e espacial. As diversas mídias de comunicação e principalmente a internet instigaram novos modelos educacionais baseados na educação à distância, com reflexos sobre a educação presencial, apesar da educação a distância não ser mérito da internet com o uso de computadores, pois já existiam métodos pedagógicos de ensino a distância por correspondência, tendo como principal ferramenta os serviços de correio. Através de relato de experiências entre as áreas de coordenação de cursos, tutoria e elaboração de materiais didáticos mediacionais buscou-se nesse trabalho verificar a evolução da tecnologia e as mudanças no contexto socioeconômico global que impactaram novos comportamentos sociais $e$, consequentemente, novas exigências no espaço da educação no sentido de promover a divulgação dos conhecimentos e da profissionalização. Nesse sentido, a conclusão que se chega com essa troca de experiências, entre diferentes áreas do Claretiano centro Universitário, é que tanto a gestão das universidades quanto a pedagogia docente tiveram que se adequar a essa nova realidade, priorizando uma educação de qualidade com destaque para a formação da consciência existencial do ser humano no planeta, que agora está inserido numa sociedade predominantemente da informação e suas formas de comunicação também se dão por meio de redes sociais, criando um novo padrão nas relações dos indivíduos, a despeito dos limites impostos pelo sistema de mercado que ainda influencia a cultura material e os valores do cidadão.

Agostinho Fernando Adami, Elvisney Aparecido Alves, Luciana Ap. Mani Adami 